\title{
A peptidyl-glucosamine derivative affects IKK $\alpha$ kinase activity in human chondrocytes
}

\author{
Anna Scotto d'Abusco ${ }^{1 *}$, Laura Politi ${ }^{1}$, Cesare Giordano ${ }^{2}$, Roberto Scandurra ${ }^{1}$
}

\begin{abstract}
Introduction: Nuclear factor- $\kappa \mathrm{B}(\mathrm{NF}-\kappa \mathrm{B})$ transcription factor regulates several cell signaling pathways, such as differentiation and inflammation, which are both altered in osteoarthritis. Inhibitor $\kappa B$ kinase (IKK) $\alpha$ and IKK $\beta$ are kinases involved in the activation of the NF- $\kappa \mathrm{B}$ transcription factor. The aim of the present study was to determine the effects of glucosamine (GlcN), which is administered in the treatment of osteoarthritis, and of its 2-(N-Acetyl)-Lphenylalanylamido-2-deoxy- $\beta$-D-glucose (NAPA) derivative on IKK kinases and, consequently, on NF- $\kappa$ B activation in human chondrocytes.

Methods: The human chondrosarcoma cell line HTB-94 and human primary chondrocytes were stimulated with tumor necrosis factor (TNF) $\alpha$ after pre-treatment with GlcN or NAPA. Gene mRNA expression level was evaluated by real-time PCR. Inhibitor $\kappa \mathrm{B}$ protein $(\mid \kappa \mathrm{B}) \alpha$ phosphorylation and p65 nuclear re-localization were analyzed by Western blotting; IKKa nuclear re-localization was also investigated by immunocytochemistry and Western blotting. IKK kinase activity was studied by in vitro kinase assay.

Results: After TNF $\alpha$ stimulation, the mRNA expression level of some of the genes under NF- $\kappa$ B control, such as interleukin (IL)- 6 and IL-8, increased, while treatment with GlCN and NAPA reverted the effect. We investigated the possibility that GlcN and NAPA inhibit IKK kinase activity and found that NAPA inhibits the IKKo kinase activity, whereas GICN does not. Interestingly, both GICN and NAPA inhibit IKK $\alpha$ nuclear re-localization.

Conclusions: Our results demonstrate that glucosamine and its peptidyl derivative can interfere with NF- $\kappa \mathrm{B}$ signaling pathway by inhibiting IKK $\alpha$ activity in human chondrocytes. However, the mechanism of action of the two molecules is not completely overlapping. While NAPA can both specifically inhibit the IKKo kinase activity and IKK $\alpha$ nuclear re-localization, GIcN only acts on IKK $\alpha$ nuclear re-localization.
\end{abstract}

\section{Introduction}

Osteoarthritis (OA), the most common rheumatic disease, is a major cause of disability. It is strongly associated with aging and its medical relevance is rising in the Western population given the increasing proportion of older people. This pathology is characterized by progressive destruction of the extracellular matrix (ECM), causing pain and disability in patients. OA is a non-curable disease and its pharmacological treatment is based mainly on analgesic agents or non-steroidal anti-inflammatory drugs (NSAIDs). Structure-modifying agents are also administered to OA patients, with the aim of preventing or delaying cartilage degradation by pharmacological treatment [1]. Several chondroprotective agents,

\footnotetext{
* Correspondence: anna.scottodabusco@uniroma1.it
'Department of Biochemical Sciences, Sapienza University of Roma, P.le Aldo

* Correspondence: anna.scottodabusco@uniroma1.it
'Department of Biochemical Sciences, Sapienza University of Roma, P.le Aldo Moro, 5, 00185 Roma, Italy
}

(c) 2010 Scotto d'Abusco et al.; licensee BioMed Central Ltd. This is an open access article distributed under the terms of the Creative

such as glucosamine $(\mathrm{GlcN})$, condroitin sulfate, diacerein and curcumin, have been studied [2-6]. To date, studies performed in vivo and in vitro on GlcN and condroitin sulfate have provided partially inconsistent results [7-11]. Since these agents are widely available and generally well tolerated and possess safer profiles compared with NSAIDs, it is important to understand their mechanism of action in detail.

We have previously studied GlcN and its $\mathrm{N}$-acetyl phenylalanine derivative (NAPA) in vivo, in an animal model and in vitro, in primary chondrocytes and in an immortalized cell line. In the in vivo study, we found that both GlcN and NAPA were very effective in reducing cartilage changes induced in rabbit knee by intraarticular injection of vitamin A [12]. In the in vitro study, GlcN and NAPA were able to counteract the effects induced by inflammatory cytokines, tumor 
necrosis factor-alpha (TNF $\alpha$ ) and interleukin (IL)- $1 \beta$, both in human primary chondrocytes and in immortalized cell line lbvpa55 [13,14]. Interestingly, we found that GlcN inhibits matrix metalloproteinase production by inhibiting the phosphorylation of the mitogen-activated protein (MAP) kinases involved in the activation of activator protein-1 (AP-1) transcription factor complex [14]. NAPA showed the same behaviour (unpublished data). Furthermore, we found that several genes upregulated by TNF $\alpha$ are modulated by GlcN and NAPA [13]. Since these genes are under the control of nuclear factor-kappa-B (NF- $\kappa$ B) transcription factor, we decided to analyze their mechanism of action in the context of the NF- $\kappa$ B pathway.

NF- $\kappa \mathrm{B}$ is a family of transcription factors that play an important role in the immune system and that can influence gene expression events with an impact on cell survival, differentiation and proliferation $[15,16]$. The mammalian NF- $\kappa \mathrm{B}$ family consists of five related transcription factors: p50, p52, p65 (RelA), c-Rel and RelB. The established model of NF- $\kappa$ B action states that, in unstimulated cells, inhibitor $\kappa \mathrm{B}$ proteins $(\mathrm{I} \kappa \mathrm{Bs})$ sequester the inactive transcription factor in the cytoplasm. Stimulatory events lead to $\mathrm{I} \kappa \mathrm{B}$ protein phosphorylation, ubiquitylation and subsequent degradation. The end result is the release of the cytoplasmic NF- $\kappa \mathrm{B}$ complex, which moves into the nucleus, where it drives the expression of its target genes [15-17]. The kinase responsible for $\mathrm{I} \kappa \mathrm{B}$ phosphorylation is the inhibitor $\kappa \mathrm{B}$ kinase (IKK) complex. Two components of the IKK complex, IKK $\alpha$ and IKK $\beta$, are involved in the release of the NF- $\kappa \mathrm{B}$ active form. Proinflammatory stimuli activate IKK $\beta$, which is essential for $\mathrm{I} \kappa \mathrm{B} \alpha$ degradation. In contrast, IKK $\alpha$ only rarely activates $\mathrm{I} \kappa \mathrm{B} \alpha$ [18] but has been reported to activate the NF- $\kappa \mathrm{B}$ pathway by working as a nucleosomal kinase $[19,20]$ that stimulates a distinct class of genes [21]. Moreover, a differential role of IKK $\alpha$ and IKK $\beta$ in the physiology and progression of OA chondrocytes was recently reported, suggesting that the OA phenotype is more related to IKK $\alpha$ than to IKK $\beta$ [22].

The aim of the present study is to investigate whether GlcN and NAPA could affect the activation of IKK $\alpha$ and IKK $\beta$ in chondrocytes stimulated with the proinflammatory cytokine TNF $\alpha$. We found that NAPA and, albeit to a lesser extent, GlcN inhibit the expression of genes under NF- $\kappa \mathrm{B}$ control. We analyzed the effect of both molecules on $\mathrm{I} \kappa \mathrm{B} \alpha$ phosphorylation and on $\mathrm{p} 65$ nuclear translocation. We also evaluated whether NAPA and GlcN could affect IKK $\alpha$ and IKK $\beta$ activation and IKK $\alpha$ nuclear translocation. To circumvent the limitations of human primary chondrocytes such as poor yield, low proliferation and inter-individual variability of donor samples, we conducted the study on the immortalized cell line HTB-94 (SW1353; American Type
Culture Collection, Manassas, VA, USA). For confirmation, some experiments were also performed on human primary chondrocytes.

\section{Materials and methods \\ Cell culture}

The HTB-94 human chondrosarcoma cell line (SW1353) was purchased from American Type Culture Collection and was grown in Dulbecco's modified Eagle's medium (DMEM) (HyClone, Logan, UT, USA) supplemented with L-glutamine, penicillin/streptomycin (HyClone), plus 10\% fetal bovine serum (FBS). Experiments were performed in DMEM containing 1\% FBS. Human primary chondrocytes were isolated as previously described [14] from cartilage obtained from healthy donors. Full ethical consent was obtained from all donors, and the experiments were performed in accordance with Sapienza University of Roma ethics committee guidelines. Cells were used at first passage in DMEM containing 1\% FBS.

\section{Cell treatment}

The HTB-94 cell line has been previously shown to be a good model to study inflammatory pathways [23]. Cells were seeded in plates at the required density. Cells were left untreated (CTL) or treated with $10 \mathrm{ng} / \mathrm{mL}$ recombinant TNF- $\alpha$ (PeproTech EC Ltd., London, UK) or pretreated for 2 hours with 5 and $10 \mathrm{mM} \mathrm{GlcN}$ (SigmaAldrich, St. Louis, MO, USA) or with 2-(N-Acetyl)-Lphenylalanylamido-2-deoxy- $\beta$-D-glucose (NAPA), synthesized as previously reported [24]. After pre-incubation, the cells were stimulated with $10 \mathrm{ng} / \mathrm{mL}$ TNF- $\alpha$ for the required time. Cells were analyzed by immunocytochemistry or harvested and processed for quantitative real-time polymerase chain reaction (Q-RT-PCR), for Western blot analysis and for immunoprecipitation.

\section{RNA extraction and reverse transcription}

Total RNA was extracted using TRIZOL reagent (Invitrogen Corporation, Carlsbad, CA, USA) in accordance with the manufacturer's instructions. Briefly, a confluent 60 -mm plate of HTB-94 or human primary chondrocytes was washed with phosphate-buffered saline (PBS) and homogenized in $1 \mathrm{~mL}$ of TRIZOL reagent. RNA was stored at $-80^{\circ} \mathrm{C}$ until used. cDNA was synthesized from $1 \mu \mathrm{g}$ of total RNA, using reverse transcriptase Improm II (Promega Corporation, Madison, WI, USA) in accordance with the manufacturer's instructions, and analyzed by Q-RT-PCR.

\section{Real-time polymerase chain reaction}

Q-RT-PCR analysis was performed using an ABI Prism 7300 (Applied Biosystems, Foster City, CA, USA). Amplification was carried out with 50 ng of cDNA, in 96-well 
plates, using SYBR Green PCR Master mix (Applied Biosystems) in a volume of $25 \mu \mathrm{L}$. Each sample was analyzed in triplicate. PCR conditions were $94^{\circ} \mathrm{C}$ for 10 minutes followed by 40 cycles of $94^{\circ} \mathrm{C}$ for 15 seconds and $60^{\circ} \mathrm{C}$ for 1 minute. Primers were designed using Primer Express software (Applied Biosystems) and were synthesized by Primm (Milan, Italy). The following primers were used: IL-6 forward, 5'-TGGCCTGAAAAAGATGGATGCT-3'; IL-6 reverse, 5'-AACTCCAAAAGACCAGTGATGATTT3' (NM_000600); IL-8 forward, 5'-AGATATTGCACGGGAGAATATACAAA-3'; IL-8 reverse, 5'-GCAAACCCATTCAATTCCTGAA-3' (NM_000584); I $\kappa \mathrm{B} \alpha$ forward, 5'-TGATCACCAACCAGCCAGAA-3'; I $\kappa \mathrm{B} \alpha$ reverse, 5'TCTCGGAGCTCAGGATCACA-3' (NM_020529); ICAM-1 forward, 5'-GGTGACCGTGAATGTGCTC-3'; ICAM-1 reverse, 5'-GCCTGCAGTGCCCATTATG-3' (NM_000201.2); Mcp-1 forward 5'-CGCTCAGCCAGATGCAATC-3'; Mcp-1 reverse, 5'-GCACTGAGATCTTCCTATTGGTGAA-3' (NM_02982); glyceraldehyde3-phosphate dehydrogenase (GAPDH) forward 5'GGAGTCAACGGATTTGGTCGTA-3'; GAPDH reverse, 5'-GGCAACAATATCCACTTTACCAGAGT-3' (NM_02046).

The results were analyzed using the Sequence Detection Systems software (Applied Biosystems), which automatically recorded the threshold cycle $\left(C_{t}\right)$. Untreated cell sample (CTL) was used as calibrator. The fold change for CTL was 1.0. Target gene $C_{t}$ values were normalized against GAPDH. Data were analyzed using the $2^{\Delta \Delta C t}$ method and expressed as fold change compared with CTL.

\section{Western blotting}

Human primary chondrocytes, treated as described above, were washed with PBS and lysated by nuclear extract kit (Active Motif, Carlsbad, CA, USA) to separate the cytosolic from the nuclear extract in accordance with the manufacturer's instructions. Extracts were resolved on $10 \%$ SDS-PAGE. Gels were transferred to Hybond C membranes (GE Healthcare Europe, Milan, Italy) by electroblotting (Bio-Rad Laboratories, Inc., Hercules, CA, USA) and probed with specific antibodies in accordance with the manufacturer's instructions. Antibodies against IKK $\alpha$ and $\beta$-actin were purchased from Sigma-Aldrich, and antibodies against fibrillarin, $\mathrm{p}-\mathrm{I} \kappa \mathrm{B} \alpha$ and p65 were from Santa Cruz Biotechnology, Inc. (Santa Cruz, CA, USA). Where indicated, the intensity of bands was compared by densitometric analysis using ImageJ 1.41 (National Institutes of Health, Bethesda, MD, USA) and reported as fold change.

\section{Immunoprecipitation of the IKK complex}

To immunoprecipitate the activated IKK complex, HTB94 cells were treated with $10 \mathrm{ng} / \mathrm{mL}$ TNF $\alpha$ for 10 minutes, scraped and homogenized in lysis buffer $\mathrm{pH}$ 7.5 (50 mM TRIS-Cl, $100 \mathrm{mM} \mathrm{NaCl}, 1 \%$ NP40, 0.25\% Na-deossycolate, $1 \mathrm{mM}$ EDTA). Whole-cell lysate (200 $\mu \mathrm{g})$ was incubated with anti-IKK $\alpha$ antibody (SigmaAldrich) at $4^{\circ} \mathrm{C}$ for 16 hours and next treated with protein A-Agarose beads (Santa Cruz Biotechnology, Inc.). After 2-hour incubation, the beads were extensively washed with lysis buffer and assayed in an in vitro kinase assay as detailed below.

\section{Kinase assay}

To determine the effect of NAPA and GlcN on TNF $\alpha$ induced IKK complex activation, we performed an immunocomplex kinase assay. Immunoprecipitated (IP)IKK complex, recombinant IKK $\alpha$ (Invitrogen Corporation) and IKK $\beta$ (Invitrogen Corporation) were analyzed by kinase assay in a mixture containing $50 \mathrm{mM}$ Tris- $\mathrm{Cl}$ $\mathrm{pH}$ 7.4, $100 \mathrm{mM} \mathrm{NaCl}, 10 \mu \mathrm{Ci} \gamma^{32}$ P-ATP (PerkinElmer Italia - Life and Analytical Sciences, Monza [Milan], Italy), $5 \mathrm{mM} \mathrm{MgCl} 2,1 \mathrm{mM}$ DTT and $2 \mu \mathrm{g}$ of substrate glutatione S-transferase (GST) I $\kappa \mathrm{B} \alpha$ (Santa Cruz Biotechnology, Inc.) in the presence or absence of different concentrations of GlcN or NAPA. Kinase assay was performed at $30^{\circ} \mathrm{C}$ for 30 minutes, and the reaction was stopped by boiling with SDS sample buffer (SigmaAldrich) for 5 minutes. Finally, the proteins were resolved on $10 \%$ SDS-PAGE and transferred to Hybond C membranes (GE Healthcare Europe) by electroblotting (Bio-Rad Laboratories, Inc.). Membrane was exposed to $\mathrm{x}$-ray film to visualize the radioactive bands. To determine the total amounts of IKK $\alpha / \beta$ in each IP sample, the same membrane was probed with anti-IKK $\alpha$ antibody.

\section{Immunocytochemistry and confocal microscopy}

IKK $\alpha$ nuclear re-localization was visualized by confocal microscopy. HTB-94 cells were untreated (CTL) or treated with $10 \mathrm{ng} / \mathrm{mL}$ TNF $\alpha$ and with GlcN or NAPA plus TNF $\alpha$. After treatment, cells were fixed with $4 \%$ paraformaldehyde and permeabilized with $0.3 \%$ Triton X-100. After washing with PBS, the cells were incubated overnight at $4^{\circ} \mathrm{C}$ with monoclonal anti-IKK $\alpha$ (sc-7606; Santa Cruz Biotechnology, Inc.) (diluted 1:50), washed with PBS and incubated for 1 hour at room temperature with Alexa Fluor 488 goat anti-mouse antibody (Invitrogen Corporation) (diluted 1:300). Slides were washed, incubated with DAPI (diamidino-2-phenylindole) (Invitrogen Corporation) to visualize nuclei, mounted and analyzed with a Leica 2500 confocal microscopy (Leica Microsystems, Wetzlar, Germany).

\section{Assessment of cell viability}

To detect potential cytotoxic effects of NAPA, the survival of the cells treated with this molecule was evaluated 
using MTT (3- [4,5-dimethylthiazol-2-yl]-2,5-di-phenyltetrazolium bromide)-based colorimetric assay (SigmaAldrich) in accordance with the manufacturer's instructions. Briefly, $1.5 \times 10^{4}$ cells per well were seeded in a 96-well plate in a volume of $150 \mu \mathrm{L}$. NAPA was added at concentrations of $1,2.5,5$ and $10 \mathrm{mM}$. Fifteen microlitres of MTT, a soluble tetrazolium salt solution, was added to the well 24, 48 and 96 hours after treatment, and the plate was incubated for an additional 4 hours. Afterwards, the culture medium was removed and 150 $\mu \mathrm{L}$ of solvent solution was added to dissolve the MTT formazan crystals. Spectrophotometric absorbance was measured at a wavelength of $570 \mathrm{~nm}$. The background at $690 \mathrm{~nm}$ was subtracted.

\section{Statistics}

Each experiment was performed at least three times. The statistical significance of the differences between mean values was determined by a two-tailed $t$ test; $P$ value of not more than 0.05 was considered significant. When appropriate, results are expressed as the mean \pm standard error of the mean.

\section{Results}

\section{GICN and NAPA prevent the overexpression of} TNF $\alpha$-stimulated genes

Previously, we found that both in immortalized cell line and in rabbit primary chondrocytes, GlcN and NAPA were able to counteract the TNF $\alpha$ upregulation of some genes, such as TNFR-1 and TNFR-2, TRAF-6 and IGFBP-6, whose transcription is under the control of NF- $\kappa \mathrm{B}[12,13]$. To explore whether GlcN and NAPA affect the NF- $\kappa$ B pathway in HTB-94 cells, we also analyzed the expression of other NF- $\kappa \mathrm{B}$-regulated genes. $I L-6, I L-8, I C A M-1, M c p-1$ and $I \kappa B \alpha$ mRNA expression levels were upregulated after 1-hour stimulation with TNF $\alpha$. Two-hour pre-treatment with $10 \mathrm{mM}$ of both molecules significantly reverted the stimulation of $I L-6$, $I L-8, I C A M-1$ and $M c p-1$, whereas the effect on $I \kappa B \alpha$ was negligible. The effect of GlcN and NAPA at a concentration of $5 \mathrm{mM}$ was not significant (Figure 1). The same result was obtained in human primary chondrocytes (data not shown).

\section{GIcN and NAPA slightly affect $I \kappa B \alpha$ phosphorylation and p65 nuclear migration}

To determine whether GlcN and NAPA affected $\mathrm{I} \kappa \mathrm{B} \alpha$ phosphorylation, we analyzed the latter protein by Western blot. $\mathrm{I} \kappa \mathrm{B} \alpha$ was significantly phosphorylated in the cytosolic extract of cells stimulated with TNF $\alpha$ for 10 minutes. A 2-hour pre-treatment with GlcN and NAPA did not significantly inhibit $\mathrm{I} \kappa \mathrm{B} \alpha$ phosphorylation (Figure 2a). Since a concentration of $5 \mathrm{mM}$ of either molecules was ineffective in modulating gene expression, the experiments were performed with only $10 \mathrm{mM}$ of both molecules. We investigated whether GlcN and
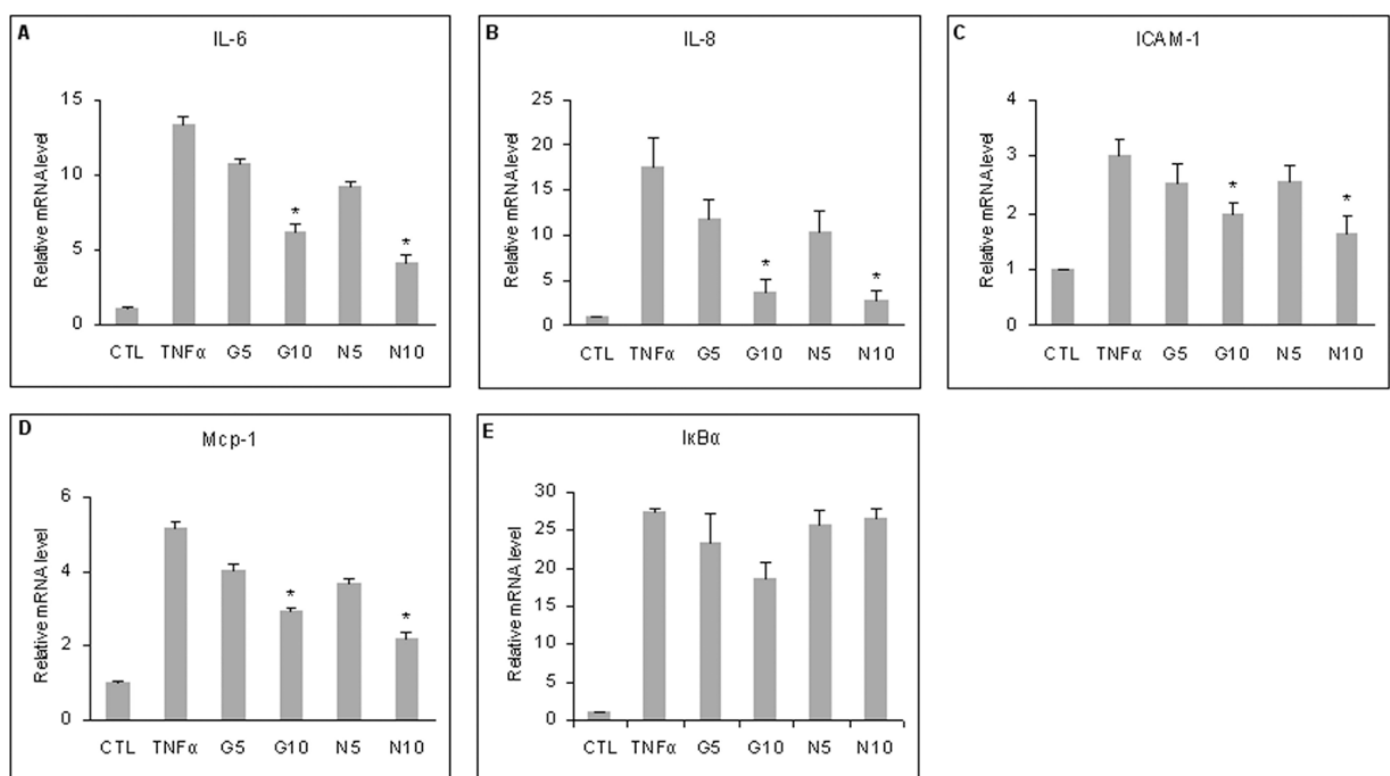

Figure 1 Effect of glucosamine (GICN) and NAPA on mRNA expression level in HTB-94 cells. Cells were untreated (CTL), treated with tumor necrosis factor-alpha (TNF $\alpha$ ) or pre-treated with 5 and $10 \mathrm{mM} \mathrm{GlcN}$ (G5 and G10) or NAPA (N5 and N10) and then stimulated with TNF $\alpha$ for 1 hour. The mRNA was extracted and analyzed by quantitative real-time polymerase chain reaction (Q-RT-PCR). The mRNA levels of IL-6, IL-8, ICAM-1, Mcp-1 and $1 \kappa B \alpha$ are shown in (a), (b), (c), (d) and (e), respectively. ${ }^{*} P \leq 0.05$. Q-RT-PCR results are expressed as relative mRNA level. Results represent the mean \pm standard error of the mean of data obtained by three independent experiments. NAPA, 2-(N-Acetyl)-Lphenylalanylamido-2-deoxy- $\beta$-D-glucose. 


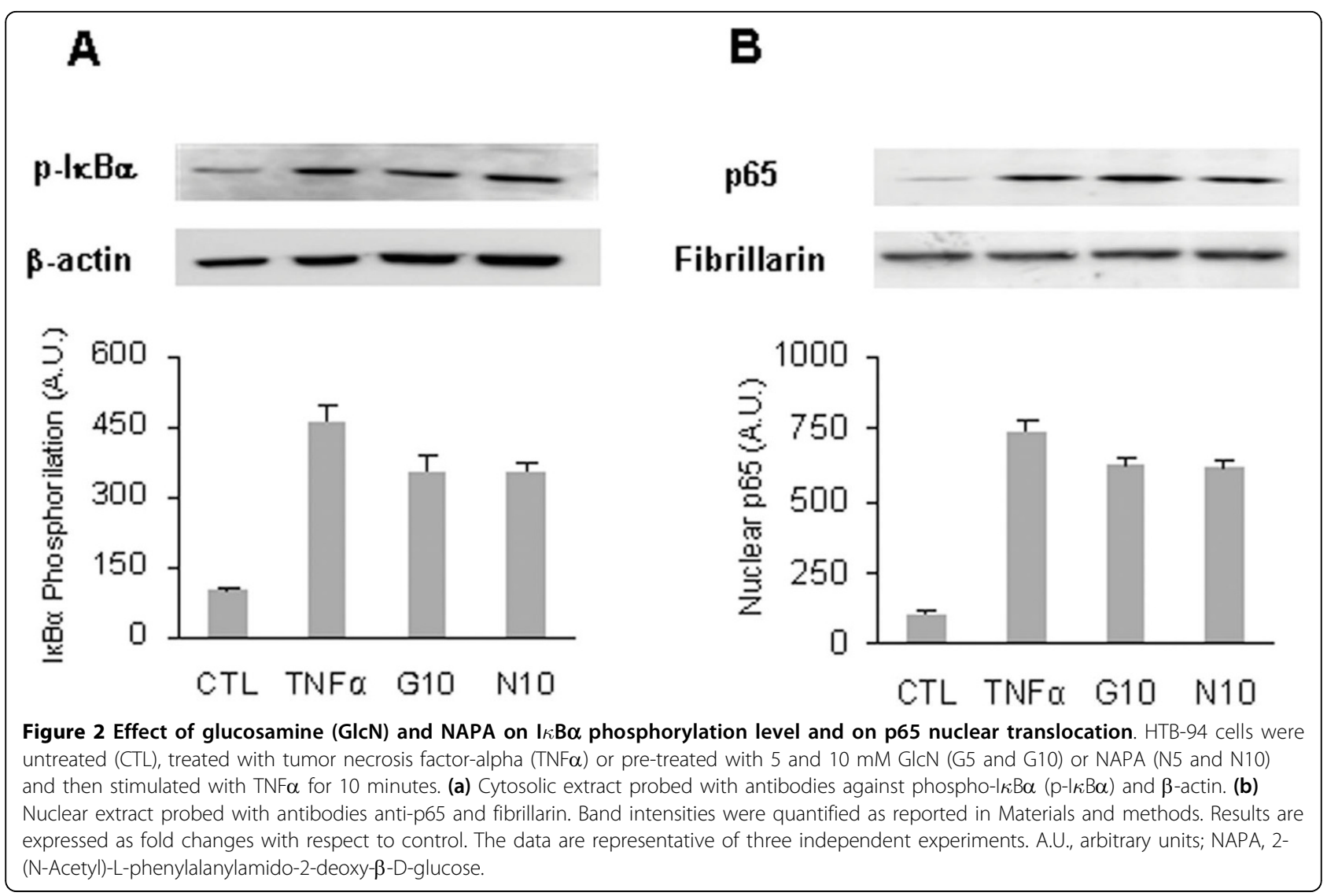

NAPA inhibit the re-localization of the p65 subunit into the nucleus. Nuclear extract of cells treated for $10 \mathrm{~min}$ utes with TNF $\alpha$ showed that p65 was localized in the nucleus, an effect only very moderately inhibited by GlcN and NAPA, as expected given their minor effect on $\mathrm{I} \kappa \mathrm{B} \alpha$ phosphorylation (Figure $2 \mathrm{~b}$ ). The same result was obtained on human primary chondrocytes (data not shown).

\section{NAPA affects the kinase activity of IKK complex}

$\mathrm{I} \kappa \mathrm{B}$ phosphorylation is mediated by the IKK complex. To determine whether GlcN and NAPA interfere with the IKK kinase activity, we treated HTB-94 cells with TNF $\alpha$ and the IKK complex was immunoprecipitated using an anti-IKK $\alpha$ antibody from whole-cell extracts. The IP-IKK complex was analyzed in an in vitro kinase assay using a recombinant GST-I $\kappa \mathrm{B} \alpha$ protein as substrate both in the absence and in the presence of GlcN and NAPA. In the first case, activated IP-IKK was able to phosphorylate GST-I $\kappa \mathrm{B} \alpha$, demonstrating that TNF $\alpha$ activates the IKK complex in our experimental model. GlcN was not able to inhibit GST-I $\kappa \mathrm{B} \alpha$ phosphorylation (Figure 3a), whereas NAPA inhibited GST-I $\kappa \mathrm{B} \alpha$ phosphorylation at a concentration of $0.5 \mathrm{mM}$ (Figure 3b). To distinguish between the effects of IKK $\alpha$ and IKK $\beta$, we analyzed the inhibition of IKK kinase activity on GST $-\mathrm{I} \kappa \mathrm{B} \alpha$ by GlcN and NAPA, using recombinant IKK $\alpha$ and IKK $\beta$ molecules. GlcN was not able to inhibit either IKK $\alpha$ or IKK $\beta$ at either concentration used $(0.25$ and $0.5 \mathrm{mM}$ ) (Figure 3c, e). On the contrary, NAPA strongly inhibited the IKK $\alpha$ kinase activity on itself and on GST-I $\kappa \mathrm{B} \alpha$ at both concentrations (Figure $3 \mathrm{~d}$ ) but did not affect the IKK $\beta$ kinase activity on itself or on GST-I $\kappa$ B $\alpha$ (Figure 3f). In these experiments, we were able to use lower concentrations of GlcN and NAPA $(0.25$ and $0.5 \mathrm{mM})$ than those used on intact cells (10 $\mathrm{mM}$ ) because the molecules can directly interact with the kinases without needing to cross the cell membrane.

\section{GICN and NAPA inhibit IKK $\alpha$ nuclear migration}

IKK $\beta$ activates the canonical NF- $\kappa \mathrm{B}$ pathway by phosphorylation of $\mathrm{I} \kappa \mathrm{B} \alpha$, whereas IKK $\alpha$ is not required to phosphorylate $\mathrm{I} \kappa \mathrm{B} \alpha$, but it plays an important role by localizing into the nucleus of activated cells and inducing the transcription of NF- $\kappa \mathrm{B}$-dependent genes. To determine whether GlcN and NAPA could inhibit the IKK $\alpha$ nuclear translocation, we analyzed its subcellular localization by immunocytochemistry. Detection of IKK $\alpha$ revealed that this protein is mainly cytoplasmic in unstimulated cells, while it accumulates in the nucleus 


\begin{tabular}{|c|c|c|c|c|c|c|c|c|c|c|c|}
\hline A & & & & C & & & & E & & & \\
\hline TNF $\alpha$ & + & + & + & IKKa & + & + & + & IKK $\beta$ & + & + & + \\
\hline GIcN mM & - & 0.25 & 0.5 & GIcN mM & - & 0.25 & 0.5 & GlcN mM & - & 0.25 & 0.5 \\
\hline GST-IxBa & $=$ & - & - & IKKa & $=$ & 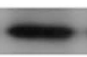 & 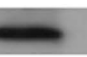 & IKK $\beta$ & - & $=$ & $\longrightarrow$ \\
\hline anti-IKKa & -2 & -2 & - & GST-IxBa & $=$ & $=$ & $2=$ & GST-Ix Ba & - & - & 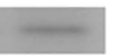 \\
\hline 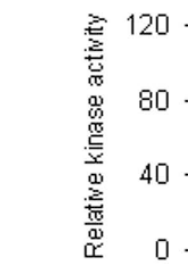 & - & $T$ & $T$ & 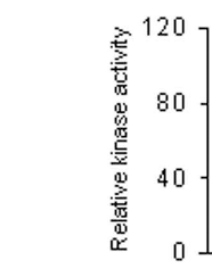 & & & $T_{T}$ & 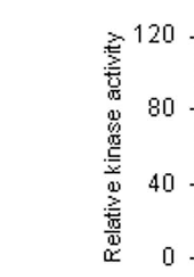 & & $T T$ & $T T$ \\
\hline B & & & & D & & & & $\mathbf{F}$ & & & \\
\hline TNF $\alpha$ & + & + & + & IKKa & + & + & + & IKK $\beta$ & + & + & + \\
\hline NAPA $m M$ & - & 0.25 & 0.5 & NAPA $m M$ & - & 0.25 & 0.5 & NAPA $m M$ & - & 0.25 & 0.5 \\
\hline GST-IxBa & $\longrightarrow$ & - & $\longrightarrow$ & IKKa & - & - & - & IKK $\beta$ & - & - & - \\
\hline anti-IKK $\alpha$ & 2 & Eas: & 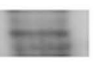 & GST-IxBa & $=1$ & $=$ & & GST-Ix $B \alpha$ & - & $\div$ & - \\
\hline 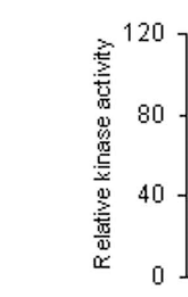 & $T$ & $T$ & $*$ & 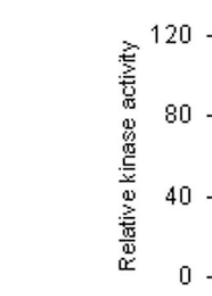 & -1 & $\stackrel{*}{T}$ & $T_{T}^{*}$ & 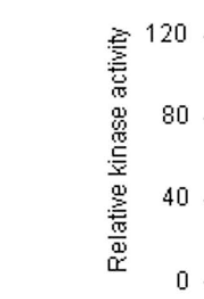 & & $T_{T}$ & $T T$ \\
\hline \multicolumn{12}{|c|}{ 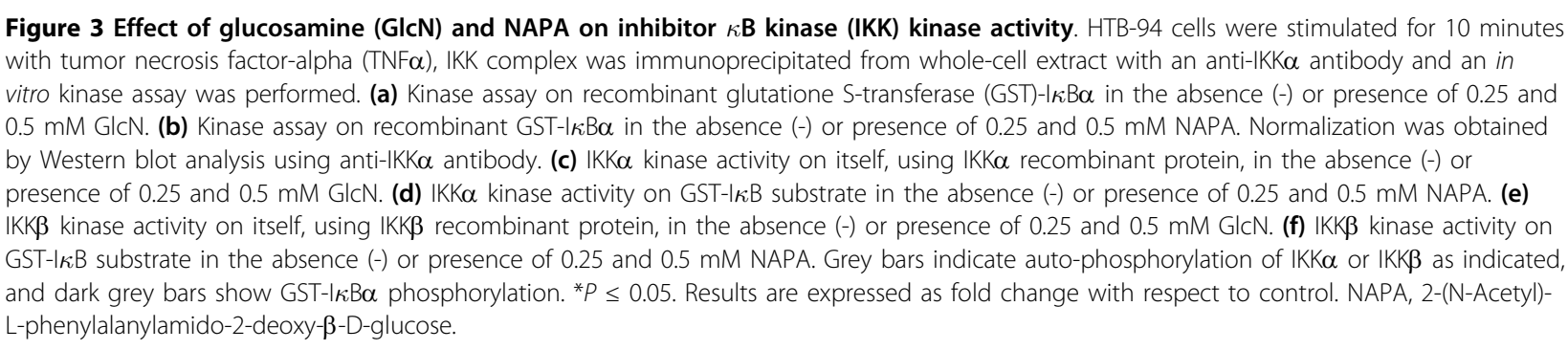 } \\
\hline
\end{tabular}

of cells stimulated with TNF $\alpha$. Cells pre-treated with GlcN and NAPA and subsequently stimulated with TNF $\alpha$ showed a prevalent cytoplasmic IKK $\alpha$ localization (Figure 4). This result was confirmed in human primary chondrocytes by Western blot analysis in which both GlcN and NAPA were able to inhibit the re-localization of IKK $\alpha$ into nuclei (Figure 5a, b).

\section{NAPA inhibits nuclear IKK $\alpha$ kinase activity on histone H3}

Several authors have shown that IKK $\alpha$, after translocating into the nucleus, phosphorylates histone $\mathrm{H} 3$, thereby permitting the transcription of several genes under NF- $\kappa \mathrm{B}$ control $[19,20,25]$. We investigated whether NAPA could inhibit the IKK $\alpha$-dependent phosphorylation of histone $\mathrm{H} 3$ and indeed found that this is the case (Figure 6a). Interestingly, GlcN does not inhibit histone $\mathrm{H} 3$ phosphorylation (Figure 6b).

\section{NAPA does not interfere with chondrocyte viability}

To assess the potential cytotoxic effect of NAPA on human chondrocytes, we performed an MTT cell viability assay. The results show that NAPA does not affect cellular viability at any investigated concentrations or times (Figure 7). 

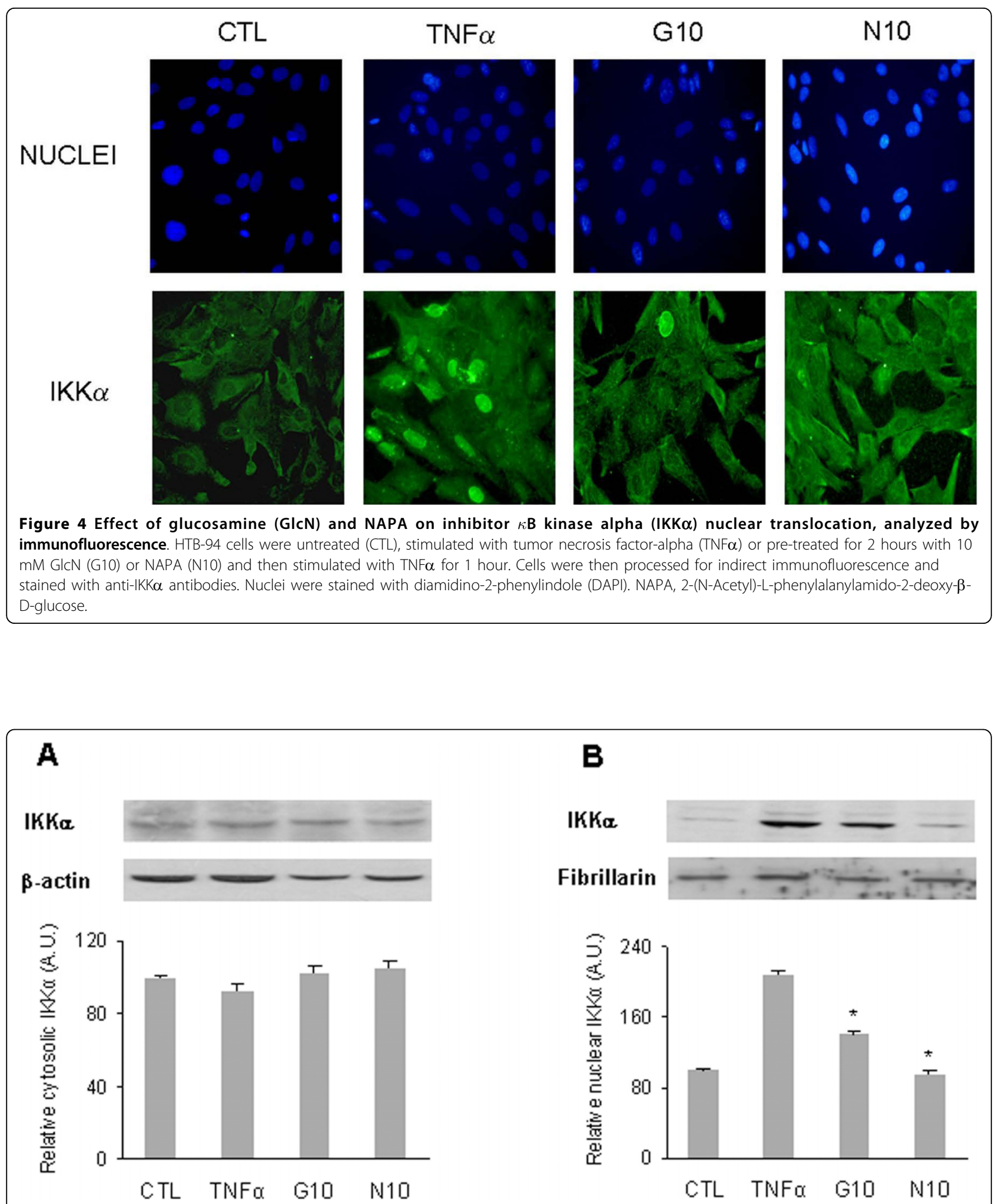

B

IKKa

Fibrillarin

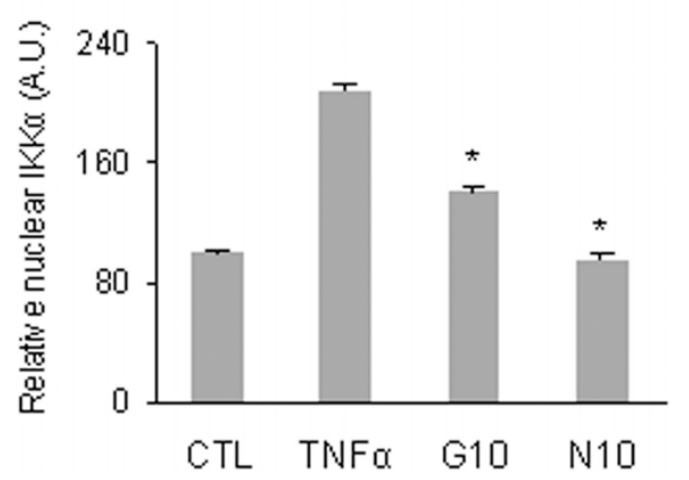

Figure 5 Effect of glucosamine (GIcN) and NAPA on inhibitor $\kappa$ B kinase alpha (IKK $\alpha$ ) nuclear translocation in human primary chondrocytes. The analysis was performed by Western blot. Cells were untreated (CTL), treated with tumor necrosis factor-alpha (TNF $\alpha$ ) or pretreated with $10 \mathrm{mM} \mathrm{GlCN}$ (G10) or NAPA (N10) and then stimulated with TNF $\alpha$ for 1 hour. (a) Cytosolic extract probed with antibodies against IKK $\alpha$ and $\beta$-actin. (b) Nuclear extract probed with antibodies against IKK $\alpha$ and fibrillarin. ${ }^{*} P \leq 0.05$. Results are expressed as fold change with respect to control. A.U., arbitrary units; NAPA, 2-(N-Acetyl)-L-phenylalanylamido-2-deoxy- $\beta$-D-glucose. 

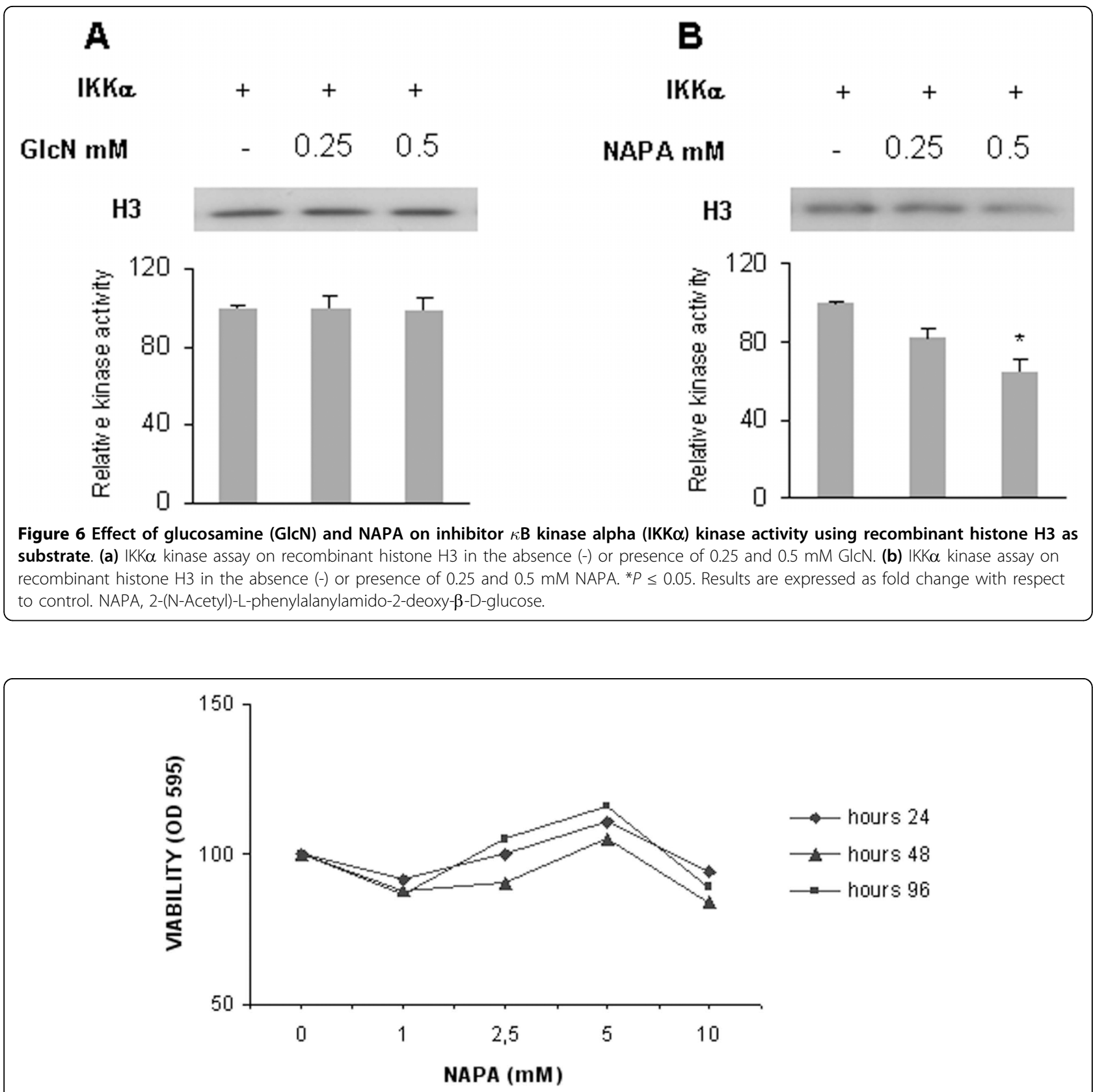

Figure 7 Effect of NAPA on cell viability. Cellular viability was assessed by MTT (3- [4,5-dimethylthiazol-2-yl]-2,5-di-phenyltetrazolium bromide) method after 24, 48 and 96 hours, with different concentrations of NAPA as indicated. NAPA, 2-(N-Acetyl)-L-phenylalanylamido-2-deoxy- $\beta$-Dglucose; OD, optical density.

\section{Discussion}

The aim of the present study was to investigate the mechanism by which GlcN and its derivative NAPA affect the activation of the NF- $\kappa \mathrm{B}$ transcription factor. $\mathrm{NF}-\kappa \mathrm{B}$ is an important regulator of the immune response but is also involved in a wide variety of stress responses and transcriptionally activates many genes with an important role in proliferation and matrix degradation.
Previously, we showed that the transcription of several genes under NF- $\kappa \mathrm{B}$ control and stimulated by TNF $\alpha$ was modulated by both molecules [13]. Here, we show that other genes under NF- $\kappa \mathrm{B}$ control, such as $I L-6, I L-$ 8, ICAM-1 and $M c p-1$, are modulated as well in the HTB-94 chondrosarcoma cell line stimulated with TNF $\alpha$. Proinflammatory cytokines can stimulate the NF- $\kappa \mathrm{B}$ pathway by activating IKK complex, which is made up of IKK $\alpha$, IKK $\beta$ and IKK $\gamma /$ NEMO. The two 
IKK $\alpha$ and IKK $\beta$ subunits are homologous kinases, whereas NEMO is a regulator subunit [26].

In the canonical NF- $\kappa B$ pathway, IKK $\beta$ is sufficient for phosphorylation of $\mathrm{I} \kappa \mathrm{B} \alpha$, leading to its degradation and thereby allowing the translocation of p50/p65 in the nucleus [27]. On the other hand, after stimulation, IKK $\alpha$ itself migrates into the nucleus, where it stimulates gene transcription [19,28-30]. We tested the ability of GlcN and NAPA to inhibit $\mathrm{I} \kappa \mathrm{B} \alpha$ phosphorylation and p65 nuclear translocation, finding that both molecules are weakly effective. Our results suggested that NF- $\kappa$ Bdependent gene modulation should be attributed to IKK $\alpha$ rather than to IKK $\beta$. In an in vitro kinase assay, we analyzed the IP-IKK complex and found that GST$\mathrm{I} \kappa \mathrm{B} \alpha$ phosphorylation was mediated by the activated complex in the absence of NAPA or GlcN. This phosphorylation was inhibited by NAPA, while no effect of GlcN was detected. To dissect the roles of IKK $\alpha$ and IKK $\beta$, we repeated the in vitro kinase assay using the individual recombinant kinases. Interestingly, we found that NAPA inhibited IKK $\alpha$-mediated auto-phosphorylation and phosphorylation of GST-I $\kappa \mathrm{B} \alpha$ but had no effect on IKK $\beta$. When IKK $\alpha$ migrates into the nucleus, it phosphorylates some substrates, derepressing the NF$\kappa \mathrm{B}$ target genes [31,32]. Among IKK $\alpha$-phosphorylated substrates is the histone $\mathrm{H} 3$, which is subsequently acetylated [25]. This is a crucial step in modulating chromatin accessibility at NF- $\kappa \mathrm{B}$ responsive promoter $[19,20]$. We found that NAPA can also inhibit H3 phosphorylation by IKK $\alpha$, suggesting that this molecule is a specific inhibitor of IKK $\alpha$ kinase activity. GlcN was not able to inhibit either IKK $\alpha$ or IKK $\beta$ kinase activity.

We tested whether TNF $\alpha$ stimulates the migration of IKK $\alpha$ into the nucleus in chondrocytes as is the case in other cell types $[19,20,25,26,33]$ and whether the effect could be inhibited by GlcN and NAPA. Indeed, TNF $\alpha$ stimulates a massive re-localization of IKK $\alpha$ into the nucleus in HTB-94 cell line and in human primary chondrocytes and both GlcN and NAPA are able to inhibit this migration. We could not detect an appreciable decrease of cytosolic IKK $\alpha$ in TNF $\alpha$-stimulated cells, because of the high concentration of IKK $\alpha$ in this compartment. This result is in accordance with what was observed in other cell types $[19,20,25,28,33]$. The effectiveness of GlcN and NAPA in inhibiting IKK $\alpha$ nuclear migration explains the ability of these molecules to modulate the expression level of genes under NF- $\kappa \mathrm{B}$ control.

Our data, in agreement with what was reported in [25], show that the absence of IKK $\alpha$ nuclear translocation and the inhibition of IKK $\alpha$ kinase activity modulate the transcription of genes under NF- $\kappa \mathrm{B}$ control, regardless of the presence of p65, which is in the nucleus of GlcN- and NAPA-treated cells. Recently, a role for IKK $\alpha$ in accelerating nuclear clearance of p65 in macrophages was reported [34]. This could explain the nuclear accumulation of p65 that we observe in chondrocytes treated with both molecules: by inhibiting IKK $\alpha$ nuclear translocation, they might impair nuclear clearance of p65. Moreover, IKK $\alpha$ enhances promoter clearance in the nucleus [31,32] and recruits and mediates the phosphorylation of proteins [35], allowing binding of p65 to $\kappa \mathrm{B}$ sequences. Consequently, the suppression of IKK $\alpha$ nuclear re-localization is expected to inhibit p65 binding.

In the IKK $\alpha$ kinase domain, a nuclear localization sequence (NLS), consisting of three lysines, Lys ${ }^{236}$. Lys $^{237}$-Lys ${ }^{238}$, is present [33]. It has been shown that inactivation of NLS by site-direct mutagenesis prevents nuclear translocation but does not interfere with its kinase activity. To inhibit IKK $\alpha$ nuclear translocation, GlcN and NAPA should interfere with the NLS presumably by interacting with the lysine residues. This is consistent with their atomic structure since they are both stable pyranose hemiacetals in equilibrium with the open form in solution. The free aldehyde groups could react with the $\mathrm{NH}_{2}$ group of the lysine side chains. NAPA affects not only the nuclear translocation but also the kinase activity of IKK $\alpha$. This is of relevance since inhibitors of enzymatic reactions are better suited for further optimization to increase their activity or pharmacokinetics properties.

It has been recently found that phenylethyl isothiocyanate shows anti-inflammatory properties acting via an attenuation of the NF- $\kappa \mathrm{B}$ pathway in cancer cells [36,37]. Like NAPA, this molecule has an aromatic ring. This feature is shared by other molecules found to inhibit NF- $\kappa$ B activity, such as aspirine and salicylate [38], aminosalicylic acid [39] and curcumin (diferuloylmethane) $[5,40]$. Consistently, the structural difference between GlcN and its derivative is indeed the presence of an aromatic phenylalanine residue.

Cell activation by TNF $\alpha$ increases the transcription of the $I \kappa B \alpha$ gene, which is under the control of the canonical NF- $\kappa$ B pathway activated by IKK $\beta[19,20,41]$. GlcN and NAPA were not able to revert this increase, and this is consistent with the finding that both molecules inhibit IKK $\alpha$ but not IKK $\beta$.

IKK $\alpha$ ablation was recently reported to show a broader range of effects on OA chondrocytes, such as enhanced ECM formation, due to the accumulation of collagen II fibers [22] and an increased chondrocyte proliferative capacity, a size reduction effect in undifferentiated chondrocytes and an enhanced survival rate of differentiated cells. It has been suggested that loss or inhibition of IKK $\alpha$ could ameliorate the degenerative aspects of OA chondrocytes, excessive ECM remodeling and increased cell death. Furthermore, since IKK $\alpha$ ablation increases the replicative potential and survival of 
OA chondrocytes, our results could be useful in the route of providing additional ways to attenuate OA progression. NAPA shows a specific effect on IKK $\alpha$ kinase activity and does not affect IKK $\beta$ kinase activity, and this makes it an interesting candidate for the treatment of the OA pathology.

\section{Conclusions}

We have previously shown that GlcN and NAPA were both effective in restoring normal cartilage morphology in injured rabbit joints and that GlcN can inhibit AP-1 activation by inhibiting MAP kinase phosphorylation. Here, we show that GlcN and NAPA can also inhibit NF- $\kappa$ B activation and, specifically, that NAPA can inhibit IKK $\alpha$ kinase activity. Further studies are required to better understand the mechanism of action of the molecule and which other effects, besides mRNA transcription modulation, can be induced in cells. It has been suggested that IKK $\alpha$ inhibition could be a good strategy for OA treatment. Our results suggest that the NAPA peptidyl-GlcN derivative should be tested in association to glucosamine in the pharmacological treatment of OA.

\section{Abbreviations}

AP-1: activator protein-1; $C_{t}$ : threshold cycle; CTL: untreated cell sample; DMEM: Dulbecco's modified Eagle's medium; ECM: extracellular matrix; FBS: fetal bovine serum; GAPDH: glyceraldehyde-3-phosphate dehydrogenase; GlcN: glucosamine; GST: glutatione S-transferase; I $\kappa$ B: inhibitor $\kappa$ B protein; IKK: inhibitor $\kappa$ B kinase; IL: interleukin; IP: immunoprecipitated; MAP: mitogen-activated protein; MTT: 3- [4,5-dimethylthiazol-2-yl]-2,5-diphenyltetrazolium bromide; NAPA: 2-(N-Acetyl)-L-phenylalanylamido-2-deoxy$\beta$-D-glucose; NF- $\kappa$ B: nuclear factor-kappa-B; NLS: nuclear localization sequence; NSAID: non-steroidal anti-inflammatory drug; OA: osteoarthritis; PBS: phosphate-buffered saline; Q-RT-PCR: quantitative real-time polymerase chain reaction; TNF $\alpha$ : tumor necrosis factor-alpha.
\end{abstract}

\section{Acknowledgements}

We thank Marina Brama for helpful assistance in performing immunocytochemistry experiments and Claudia Cicione, Silvia Chichiarelli, Kenneth Marcu and Maria Rosa Borzi for helpful discussion. A special thanks is given to Anna Tramontano for critical revision of the manuscript. This work was supported by 'Progetto di Facoltà' Sapienza, University of Rome.

\section{Author details}

${ }^{1}$ Department of Biochemical Sciences, Sapienza University of Roma, P.le Aldo Moro, 5, 00185 Roma, Italy. ${ }^{2}$ Institute of Biomolecular Chemistry, CNR, Sapienza University of Rome, P.le Aldo Moro, 5, 00185 Roma, Italy.

\section{Authors' contributions}

ASd'A conceived the design of the study, carried out the cell cultures, performed Q-RT-PCR, coordinated and trained others to perform the experiments, participated in statistical analysis and coordinated all phases of manuscript writing. CG carried out NAPA synthesis. LP and RS coordinated the laboratory work, participated in analyzing the data and helped to draft the manuscript. All authors read and approved the final manuscript.

\section{Competing interests}

The authors have filed a patent application based on the present work: patent pending number RM 2009 A000369.

Received: 20 July 2009 Revisions requested: 26 August 2009

Revised: 2 December 2009 Accepted: 29 January 2010

Published: 29 January 2010
References

1. Richette $P$, Bardin T: Structure-modifying agents for osteoarthritis: an update. Joint Bone Spine 2004, 71:18-23.

2. Shikhman AR, Kuhn K, Alaaeddine N, Lotz M: N-acetylglucosamine prevents IL-1 beta-mediated activation of human chondrocytes. J Immunol 2001, 166:5155-5160.

3. Gouze JN, Bordji K, Gulberti S, Terlain B, Netter P, Magdalou J, FournelGigleux S, Ouzzine M: Interleukin-1beta down-regulates the expression of glucuronosyltransferase I, a key enzyme priming glycosaminoglycan biosynthesis: influence of glucosamine on interleukin-1beta-mediated effects in rat chondrocytes. Arthritis Rheum 2001, 44:351-360.

4. Dodge GR, Jimenez SA: Glucosamine sulfate modulates the levels of aggrecan and matrix metalloproteinase- 3 synthesized by cultured human osteoarthritis articular chondrocytes. Osteoarthritis Cartilage 2003, 11:424-432.

5. Schulze-Tanzil G, Mobasheri A, Sendzik J, John T, Shakibaei M: Effects of curcumin (diferuloylmethane) on nuclear factor kappaB signaling in interleukin-1beta-stimulated chondrocytes. Ann N Y Acad Sci 2004 1030:578-586.

6. Dougados $M$, Nguyen $M$, Berdah $L$, Maziéres $B$, Vignon $E$, Lequesne $M$ : Evaluation of the structure-modifying effects of diacerein in hip osteoarthritis: ECHODIAH, a three-year, placebo-controlled trial. Evaluation of the Chondromodulating Effect of Diacerein in OA of the Hip. Arthritis Rheum 2001, 44:2539-2547.

7. Reginster JY, Deroisy R, Rovati LC, Lee RL, Lejeune E, Bruyere O, Giacovelli G, Henrotin $Y$, Dacre JE, Gosset C: Long-term effects of glucosamine sulphate on osteoarthritis progression: a randomised, placebo-controlled clinical trial. Lancet 2001, 357:251-256.

8. Pavelka K, Gatterova J, Olejarova M, Machacek S, Giacovelli G, Rovati LC: Glucosamine sulphate use and delay of progression of knee osteoarthritis: a 3-year, randomized, placebo-controlled, double-blind study. Arch Intern Med 2002, 162:2113-2123.

9. Clegg DO, Reda DJ, Harris CL, Klein MA, O'Dell JR, Hooper MM, Bradley JD, Bingham CO, Weisman MH, Jackson CG, Lane NE, Cush JJ, Moreland LW, Schumacher HR Jr, Oddis CV, Wolfe F, Molitor JA, Yocum DE, Schnitzer TJ, Furst DE, Sawitzke AD, Shi H, Brandt KD, Moskowitz RW, Williams HJ: Glucosamine, chondroitin sulfate, and the two in combination for painful knee osteoarthritis. N Engl J Med 2006, 354:795-808.

10. Sawitzke $A D$, Shi $H$, Finco MF, Dunlop DD, Bingham $C O$, Harris $C L$, Singer NG, Bradley JD, Silver D, Jackson CG, Lane NE, Oddis CV, Wolfe F, Lisse J, Furst DE, Reda DJ, Moskowitz RW, Williams HJ, Clegg DO: The effect of glucosamine and/or chondroitin sulfate on the progression of knee osteoarthritis: a report from the glucosamine/chondroitin arthritis intervention trial. Arthritis Rheum 2008, 58:3183-3191.

11. Toegel S, Wu SQ, Piana C, Unger FM, Wirth M, Goldring MB, Gabor F, Viernstein $\mathrm{H}$ : Comparison between chondroprotective effects of glucosamine, curcumin, and diacerein in IL-1beta-stimulated C-28/I2 chondrocytes. Osteoarthritis Cartilage 2008, 16:1205-1212.

12. Scotto d'Abusco A, Corsi A, Grillo MG, Cicione C, Calamia V, Panzini G, Sansone A, Giordano C, Politi L, Scandurra R: Effects of intra-articular administration of glucosamine and a peptidyl-glucosamine derivative in a rabbit model of experimental osteoarthritis: a pilot study. Rheumatol Int 2008, 28:437-443.

13. Scotto d'Abusco A, Cicione C, Calamia V, Negri R, Giordano C, Grigolo B, Politi L, Scandurra R: Glucosamine and its N-acetyl-phenylalanine derivative prevent TNF-alpha-induced transcriptional activation in human chondrocytes. Clin Exp Rheumatol 2007, 25:847-852.

14. Scotto d'Abusco A, Calamia V, Cicione C, Grigolo B, Politi L, Scandurra R Glucosamine affects intracellular signalling through inhibition of mitogen-activated protein kinase phosphorylation in human chondrocytes. Arthritis Res Ther 2007, 9:R104.

15. Hayden MS, Ghosh S: Shared principles in NF-kappaB signaling. Cell 2008, 132:344-362.

16. Ghosh S, Hayden MS: New regulators of NF-kappaB in inflammation. Nat Rev Immunol 2008, 8:837-848.

17. Hoffmann A, Natoli G, Ghosh G: Transcriptional regulation via the NFkappaB signaling module. Oncogene 2006, 25:6706-6716.

18. Hansberger MW, Campbell JA, Danthi P, Arrate P, Pennington KN, Marcu KB, Ballard DW, Dermody TS: IkappaB kinase subunits alpha and gamma are required for activation of NF-kappaB and induction of apoptosis by mammalian reovirus. J Virol 2007, 81:1360-1371. 
19. Anest V, Hanson JL, Cogswell PC, Steinbrecher KA, Strahl BD, Baldwin AS: A nucleosomal function for IkappaB kinase-alpha in NF-kappaB-dependent gene expression. Nature 2003, 423:659-663.

20. Yamamoto Y, Verma UN, Prajapati S, Kwak YT, Gaynor RB: Histone H3 phosphorylation by IKK-alpha is critical for cytokine-induced gene expression. Nature 2003, 423:655-659.

21. Massa PE, Li X, Hanidu A, Siamas J, Pariali M, Pareja J, Savitt AG, Catron KM, Li J, Marcu KB: Gene expression profiling in conjunction with physiological rescues of IKKalpha-null cells with wild type or mutant IKKalpha reveals distinct classes of IKKalpha/NF-kappaB-dependent genes. J Biol Chem 2005, 280:14057-14069.

22. Olivotto E, Borzi RM, Vitellozzi R, Pagani S, Facchini A, Battistelli M, Penzo M, Li X, Flamigni F, Li J, Falcieri E, Facchini A, Marcu KB: Differential requirements for IKKalpha and IKKbeta in the differentiation of primary human osteoarthritic chondrocytes. Arthritis Rheum 2008, 58:227-239.

23. Mengshol JA, Vincenti MP, Brinckerhoff CE: IL-1 induces collagenase-3 (MMP-13) promoter activity in stably transfected chondrocytic cells: requirement for Runx-2 and activation by p38 MAPK and JNK pathways. Nucleic Acids Res 2001, 29:4361-4372.

24. Giordano C, Gallina C, Consalvi V, Scandurra R: Synthesis and properties of D-glucosamine N-peptidyl derivatives as substrate analog inhibitors of papain and cathepsin B. Eur J Med Chem 1991, 26:753-762.

25. Park GY, Wang X, Hu N, Pedchenko TV, Blackwell TS, Christman JW: NIK is involved in nucleosomal regulation by enhancing histone $\mathrm{H} 3$ phosphorylation by IKKalpha. J Biol Chem 2006, 281:18684-18690.

26. Häcker H, Karin M: Regulation and function of IKK and IKK-related kinases. SCi STKE 2006, 2006(357):re13.

27. Perkins ND: Post-translational modifications regulating the activity and function of the nuclear factor kappa B pathway. Oncogene 2006 , 25:6717-6730.

28. Gloire G, Horion J, El Mjiyad N, Bex F, Chariot A, Dejardin E, Piette J: Promoter-dependent effect of IKKalpha on NF-kappaB/p65 DNA binding. $J$ Biol Chem 2007, 282:21308-21318.

29. Gloire G, Dejardin E, Piette J: Extending the nuclear roles of IkappaB kinase subunits. Biochem Pharmacol 2006, 72:1081-1089.

30. Natoli G, Saccani S, Bosisio D, Marazzi I: Interactions of NF-kappaB with chromatin: the art of being at the right place at the right time. Nat Immunol 2005, 6:439-445.

31. Hoberg JE, Yeung F, Mayo MW: SMRT derepression by the IkappaB kinase alpha: a prerequisite to NF-kappaB transcription and survival. Mol Cell 2004, 16:245-255.

32. Hoberg JE, Popko AE, Ramsey CS, Mayo MW: IkappaB kinase alphamediated derepression of SMRT potentiates acetylation of RelA/p65 by p300. Mol Cell Biol 2006, 26:457-471.

33. Sil AK, Maeda S, Sano Y, Roop DR, Karin M: IkappaB kinase-alpha acts in the epidermis to control skeletal and craniofacial morphogenesis. Nature 2004, 428:660-664.

34. Lawrence T, Bebien M: IKKalpha in the regulation of inflammation and adaptive immunity. Biochem Soc Trans 2007, 35:270-272.

35. Chariot A: The NF-kappaB-independent functions of IKK subunits in immunity and cancer. Trends Cell Biol 2009, 19:404-413.

36. Jeong WS, Kim IW, Hu R, Kong AN: Modulatory properties of various natural chemopreventive agents on the activation of NF-kappaB signaling pathway. Pharm Res 2004, 21:661-670.

37. Prawan A, Saw CL, Khor TO, Keum YS, Yu S, Hu L, Kong AN: Anti-NFkappaB and anti-inflammatory activities of synthetic isothiocyanates: effect of chemical structures and cellular signaling. Chem Biol Interact 2009, 179:202-211.

38. Yin MJ, Yamamoto Y, Gaynor RB: The anti-inflammatory agents aspirin and salicylate inhibit the activity of I(kappa)B kinase-beta. Nature 1998, 396:77-80.

39. Yan F, Polk DB: Aminosalicylic acid inhibits IkappaB kinase alpha phosphorylation of IkappaBalpha in mouse intestinal epithelial cells. J Biol Chem 1999, 274:36631-36636.

40. Aggarwal S, Ichikawa H, Takada Y, Sandur SK, Shishodia S, Aggarwal BB: Curcumin (diferuloylmethane) down-regulates expression of cell proliferation and antiapoptotic and metastatic gene products through suppression of IkappaBalpha kinase and Akt activation. Mol Pharmacol 2006, 69:195-206.
41. Hoffmann A, Leung TH, Baltimore D: Genetic analysis of NF-kappaB/Rel transcription factors defines functional specificities. EMBO J 2003, 22:5530-5539.

doi:10.1186/ar2920

Cite this article as: Scotto d'Abusco et al:: A peptidyl-glucosamine derivative affects IKK $\alpha$ kinase activity in human chondrocytes. Arthritis Research \& Therapy 2010 12:R18.

\section{Submit your next manuscript to BioMed Central and take full advantage of:}

- Convenient online submission

- Thorough peer review

- No space constraints or color figure charges

- Immediate publication on acceptance

- Inclusion in PubMed, CAS, Scopus and Google Scholar

- Research which is freely available for redistribution

Submit your manuscript at www.biomedcentral.com/submit
Biomed Central 